\title{
ARTE, INDÚSTRIA CULTURAL E EDUCAÇÃO
}

Luci Mara Bertoni*

\begin{abstract}
RESUMO: A necessidade, cada vez mais crescente, da busca de felicidade tem feito com que as pessoas se deixem influenciar pelo consumo desmedido dos produtos ofertados pela Indústria Cultural, fazendo da arte, de modo especial, da música, um meio de tornar-se igual sem perceber que estão se colocando à margem de sua própria cultura. Neste sentido, é necessário repensar quais são as contribuiçōes da educação no intuito de formar para a emancipação e para a resistência, segundo as concepções adornianas.
\end{abstract}

Palavras-chave: Arte, Indústria Cultural, Educação, Cultura, Música

As reflexões sobre as influências da Indústria Cultural na educação têm permeado as discussōes entre os pesquisadores que procuram compreender a mudança de valores e de práticas socioculturais entre os indivíduos, em grande parte promovida pela mídia. Esta mudança de valores também vem ocorrendo nas Artes (dança, música, artes plásticas).

Com relação à música, Adorno (1986), usando categorias marxistas, destaca que a mudança se dá quanto ao valor de troca e não quanto ao de uso, ou seja, trata-se de um significado de exploração através da Indústria Cultural. Exploração esta que perpassa as "ondas" de violência física, mental e social que repercutem nas atitudes dos que se deixam iludir pelo apelo de felicidade veiculado pelos meios de comunicação de massa. Adorno (op. cit., p. 114) chega a afirmar que

o cinema e o rádio não precisam mais se apresentar como arte. A verdade é que não passam de um negócio, sendo utilizados como veículos ideológicos destinados a legitimar o lixo que propositadamente produzem. Eles definem a si mesmos como indústrias e as cifras publicadas dos rendimentos de seus diretores gerais suprimem toda dúvida quanto à necessidade social de seus produtos.

\footnotetext{
* Aluna do Programa de Pós-Graduação em Educação Escolar na FCL/Unesp/Araraquara; membro do Grupo de Estudos e Pesquisas: Indústria Cultural e Educação. E-mail: lumabertoni@hotmail.com
} 
Esta "necessidade social" destacada por Adorno seria a busca de uma "identidade coletiva", pela qual o indivíduo precisa consumir os produtos da Indústria Cultural para se sentir parte de um todo. Porém, um todo ilusório, porque esta busca do coletivo, do "sentir-se igual" acaba por reforçar a marginalidade cultural a que está destinada a maioria da população já marginalizada economicamente.

Quando a Indústria Cultural privilegia um produto pseudo-artístico padronizado, calculado tecnicamente para surtir efeitos determinados de modo a serem por todos desejados e repetidos, na forma e na medida adequados a garantir o poder e o lucro do sistema dominante, gera uma necessidade compulsiva generalizada que afasta o "não-idêntico" como exótico, indesejado, incômodo ou doente. Tal repetição vem camuflada com outros produtos que, não obstante a variação aparente, repetem os mesmos modelos, esquemas ou características impostas, tendendo a manter o público sob controle, cada vez mais massificado, inconsciente e compulsivamente preso à corrente de produção. (Reis, 1996, p. 44-45)

Como conseqüência dessa massificação, podemos considerar que o fato de se ter acesso somente à cultura de massa acaba por não permitir ao indivíduo a aquisição do conhecimento de outros aspectos culturais que expressam a cultura do povo, seus valores e suas lutas. Em nosso entender, a música é a expressão do pensar e do sentir das pessoas de uma determinada época. Além de proporcionar prazer, ela também pode informar e conscientizar. Portanto, para nós, esta postura de consumo significa estar à margem da cultura como um todo. $\mathrm{O}$ indivíduo sente-se marginalizado por não compartilhar da aquisição dos produtos ofertados pela Indústria Cultural e, ao mesmo tempo, passa a ser discriminado por não se sentir "idêntico". Ele não percebe que partilhando da "cultura de massa" é que está se colocando à margem do entendimento de sua própria cultura.

Adorno (apud Reis, 1996, p. 45), em seu ensaio "Sobre música popular", considera que a Indústria Cultural prostitui os valores estéticos da arte, dando-lhe uma falsa imagem. Ele destaca, também, que a música tornou-se um fundo convencionalmente necessário e repetitivo. $\mathrm{O}$ público a escuta de forma infantil ou não a escuta. Vemos que essa crítica é muito atual quando sintonizamos qualquer emissora de rádio ou de televisão preocupadas, tão somente, com o sentido mercadológico da arte musical. Os ritmos e as letras das músicas são sempre idênticos, não acrescentando absolutamente nada à nossa formação cultural e como pessoa. Esta mercantilização da música revela, também, que muitos músicos são escravos das gravadoras, até por questões de sobrevivência. 
No Brasil, somente músicos de sucesso ainda têm a liberdade ou a iniciativa de lançarem suas músicas, "nadando contra a corrente" do fazer música somente por interesse de vender um produto. Porque a mediocridade vigente em matéria de música, como nos outros campos da arte e da cultura, tem revelado as características da lógica de consumo que visa subordinar a difusão cultural à lei de mercado. Estes músicos, porém, com sua resistência, podem desenvolver um trabalho de qualidade, estimulando a inteligência, a imaginação e a criatividade das pessoas.

As implicações da chamada "música de mercado" influenciam, tanto no aspecto cultural como no social, a formação das crianças. De maneira especial, seduzem-nas pela sensualidade das danças e das letras musicais, acarretando um desenvolvimento precoce de aspectos da sexualidade que atropelam, de alguma forma, seu desenvolvimento afetivo. Isso sem falar em outros aspectos, pois o vocabulário pobre e equivocado de muitas músicas acaba por interferir, também, em seu processo de desenvolvimento cognitivo. No dizer de Adorno (1999, p. 67), a música atual, ao invés de entreter, parece contribuir "para o emudecimento dos homens, para a morte da linguagem como expressão, para a incapacidade de comunicação". Adorno continua:

A música de entretenimento preenche os vazios do silêncio que se instalam entre as pessoas deformadas pelo medo, pelo cansaço e pela docilidade de escravos sem exigências. Assume ela em toda parte, e sem que se perceba, o trágico papel que lhe competia ao tempo e na situação específica do cinema mudo. A música de entretenimento serve ainda - e apenas - como fundo. Se ninguém mais é capaz de falar realmente, é óbvio também que já ninguém é capaz de ouvir. (Ibidem)

Aos poucos, parece que estamos caminhando para a completa falta de comunicação entre as pessoas. Entretanto, não parece contraditório pensar em perda de comunicação quando somos cada vez mais atingidos pelos novos instrumentais tecnológicos, em que as distâncias virtuais fazem-se menores a cada instante? Será mesmo que "tanto vai nos trabalhando o progresso, que dentro em pouco tempo, ficaremos barbarizados”, como já temiam os deputados, no século passado (Anais da Câmara dos Deputados, 1838, apud Haidar, 1972 [?]). Como pensar em uma educação para emancipação, como nos propõe Adorno (1995), quando a nossa cultura social e escolar nos remete a situações de semiformação? O que pode fazer e o que tem feito a escola diante desta situação?

Em uma breve reflexão sobre a educação formal e a arte, constatamos muitas mudanças nos currículos com relação a esta última. A música, por 
exemplo, foi perdendo espaço e importância como "conteúdo" da chamada Educação Artística. Pois as mudanças curriculares trazidas pelo regime pós64 substituem as aulas de música e desenho por Educação Artística, partindose, talvez, "da constatação de que a arte é uma só e de que suas expressões se intercomunicam" (Ramos-de-Oliveira, 1998, p. 39).

O ensino de Educação Artística torna-se parte obrigatória do currículo escolar a partir da lei $\mathrm{n}^{\circ} 5.692 / 71$. Mais recentemente, a nova Lei de Diretrizes e Bases da Educação Nacional (lei no 9.394/96), no art. $26 \$ 2^{\circ}$, dispõe que "o ensino da arte constituirá componente curricular obrigatório, nos diversos níveis da educação básica, de forma a promover o desenvolvimento cultural dos alunos". Embora a arte ou a educação artística faça parte das disciplinas obrigatórias dos currículos, na prática, percebemos sua desvalorização crescente, aliada às aulas de Educação Física, por exemplo. $\mathrm{O}$ ensino da arte que, segundo as diretrizes dos Parâmetros Curriculares Nacionais (PCN, 1997), engloba o ensino das Artes Visuais, da Dança, da Música e do Teatro, acaba ficando limitado a uma ou duas aulas semanais. Isto quando estas aulas são efetivamente ministradas, pois alguns professores, de maneira particular os dos Ciclos Iniciais do Ensino Fundamental, responsáveis por todas as disciplinas, preferem trabalhar os "conteúdos das matérias mais importantes" e, simplesmente, registrar aulas de Arte que nunca foram dadas. Em suas concepções, este tipo de ensino "não acrescenta nada ao aluno". Esta, evidentemente, não é uma concepção de todos os professores e não podemos generalizar suas atitudes. Há aqueles preocupados com o desenvolvimento da criticidade e da criatividade de seus alunos. Tais aspectos, entretanto, não parecem ser consensuais. Por isso, para pensarmos em uma educação voltada para a formação do aluno, é preciso, também, pensarmos na formação de seus professores.

$\mathrm{Na}$ concepção adorniana, "a única concretização efetiva da emancipação consiste em que aquelas poucas pessoas interessadas nesta direção orientem toda a sua energia para que a educação seja uma educação para a contradição e para a resistência” (Adorno, 1995, p. 183). Não se trata aqui de repensarmos a formação dos professores, pois não é este nosso objetivo. Trata-se, contudo, de revermos nossas atitudes e conformismos diante dos inúmeros apelos de busca de felicidade que nos são impostos, incitandonos ao consumo desmedido do que chamam de arte, sob o pretexto de convencer-nos de que somos iguais e usufruímos dos mesmos benefícios e da mesma cultura. Pois os professores são, do mesmo modo como seus alunos, consumidores, igualmente submetidos às sugestôes da mídia e por ela influenciados. 
Para Adorno, "as pessoas aceitam com maior ou menor resistência aquilo que a existência dominante apresenta à sua vista e ainda por cima lhes inculca à força, como se aquilo que existe precisasse existir dessa forma" (idem, p. 178). Resta-nos aceitar ou resistir à manipulação feita através da Indústria Cultural para conquistarmos nossa emancipação na busca efetiva de nossa própria cultura, procurando não nos deixar enganar pelos modismos e por uma falsa igualdade em nome da identificação com o coletivo.

\title{
Art, Cultural Industry and Education
}

\begin{abstract}
The increasing need for the search of happiness has made people become influenced by uncontrolled consuming of products offered by Cultural Industry, turning art, and specially music, a means of being equal. In this way they do not realize that they are placing themselves at the edge of their own culture. In this sense it is necessary to think again which are the contributions of education to prepare for emancipation and resistance according to adornian conceptions.
\end{abstract}

Key words: Art, Cultural Industry, Education, Culture, Music.

Referências bibliográficas

ADORNO, Theodor W. \& HORKHEIMER, Max. Dialética do Esclarecimento: Fragmentos filosóficos. Trad. de Guido Antonio de Almeida. Rio de Janeiro: Zahar, 1986.

ADORNO, Theodor W. "O fetichismo na música e a regressão da audição". Trad. de Luiz João Baraúna. Os Pensadores. São Paulo: Nova Cultural, 1999.

Educação e emancipação. Trad. de Wolfgang Leo Maar. Rio de Janeiro: Paz e Terra, 1995.

BRASIL. Lei Federal no 5.692, 11 de ago. 1971. Fixa as Diretrizes e Bases para o Ensino de $1^{\circ}$ e $2^{\circ}$ Graus. Brasília, 1971.

BRASIL. Lei Federal no 9394, 20 dez. 1996. Estabelece as Diretrizes e Bases da Educação Nacional. Brasília, 1996.

HAIDAR, M. de L.M. O ensino secundário no Império brasileiro. São Paulo: Gryallo/Edusp, 1972. 
PARÂMETROS Curriculares Nacionais: Arte. Vol. VI. Secretaria de Educação Fundamental. Brasília: MEC/SEF, 1997.

RAMOS-DE-OLIVEIRA, Newton. "Reflexões sobre a educação danificada”. In: Zuin, A.A.S., Pucci, Bruno \& Ramos-De-Oliveira, Newton (Orgs.). A Educação danificada: Contribuições à Teoria Crítica da Educação. Petrópolis: Vozes/São Carlos: Universidade Federal de São Carlos, 1997.

REIS, Sandra. Elementos de uma filosofia da educação musical em Theodor W. Adorno. Belo Horizonte: Mãos Unidas, 1996. 